\title{
INTERVENING WITH YOUTH IN THE TRANSITION FROM CARE TO INDEPENDENT LIVING
}

\author{
Varda R. Mann-Feder \\ Associate Professor, Department of Applied Human Sciences, Concordia University, \\ Montreal, Quebec, Canada
}

\begin{abstract}
This article outlines recommendations for intervention with youth transitioning to independent living based on the results of the author's own program of qualitative research, literature on the theory of Emerging Adulthood, and recent findings in relation to the experiences of youth leaving home to live on their own. The emphasis is on designing services that can more closely approximate the normative transition to adulthood.
\end{abstract}

\section{Keywords: Youth in Care, Independent Living, Home Leaving}

The author wishes to acknowledge the invaluable contributions of Emma Sobel and Allison Eades to her program of research

Youth leaving care for independent living face enormous challenges. They often experience a period of crisis that begins prior to discharge and may extend well beyond their departure from care (Mann-Feder \& White, 2004), potentially threatening their post discharge adjustment for years to come. The child and youth care workers who intervene with young people in this complex and difficult transition have a particularly demanding mandate. This article overviews findings from the authors' own program of qualitative research and outlines implications for working with youth aging out of care. The earliest studies documented the experiences of youth leaving care for independent living (Mann-Feder \& White, 2004) as well as the perceptions of staff in relation to organizational factors that facilitated youth transitions (Mann-Feder \& Guerard, 2008).

The results of prior studies have been summarized elsewhere and are available on line at http://www/childrenwebmag.com/c/articles/fice-helsinki-congress-2008. The most recent study, funded by the Social Sciences and Humanities Reseach Council of Canada, is still in progress. It builds on first person accounts of the home leaving experiences of youth in the community to identify protective factors that can promote adjustment in the transition to adulthood (Mann-Feder, Eades, \&Sobel, 2010).

A significant proportion of youth in care never return home and have no choice but to move out on their own when placement ends because of their age. Estimates from 2001 suggest that there are over 60,000 young people in care every year in Canada, 6,000 of whom leave to live on their own (Flynn, 2003). In the United States, out of the approximately 542,000 youth in care, 20,000 young adults will exit for independent living annually (Osgood, Foster, Flanagan, \& Ruth, 2005). These youth, many 
of whom were neglected or abused, separated from their families, and brought up in a system of care, are then expected to adjust to the withdrawal of services and the necessity of transitioning to adulthood with minimal supports. Findings of numerous outcome studies to date are remarkably consistent:Youth leaving care for independent living do not fare well as adults (Tweddle, 2007). They are overrepresented among the homeless, in prisons, and in adult psychiatric wards. Many do not finish high school and struggle chronically with unemployment and underemployment. Few can rely on either emotional or financial support from family (Stein, 2006).

Most child welfare practice in North America focuses on family reinsertion as the best possible outcome when children are placed (Child Welfare Gateway, 2006). When resources allow, intensive intervention efforts are directed at improving family functioning so that young people can grow up at home. Those youth who do leave to live on their own usually do so as a default option, because efforts at family reunification have failed (Mann-Feder \& Guerard, 2008). A plan for independent living develops as a response to a youth-in-care's advancing age and the inability of family and extended family to receive them. Thus, every such discharge plan is infused with loss and represents a failure for both a young person and their professional caregivers (Mann-Feder \& White, 2004). Youth who age out of care and transition to independent living are also among the most compromised youth in the care system to begin with, because they have had the least family support throughout their stay in placement. Extended years in care may have magnified the deficits they entered with when first placed. These youth are forced to live independently at a much younger age than other young people, almost ten years earlier given current statistics on home leaving (Rutman, Barlow, Alusik, Hubberstay, \& Brown, 2003). Despite their age, and irrespective of their level of readiness, they face the need to adapt to an adult lifestyle prematurely while adjusting to the termination of care.

Moving out on one's own for the first time and leaving care are experiences fraught with ambivalence (Mann-Feder \& Garfat, 2006). Independent living, for every young person, demands the relinquishment of the dependencies of childhood, which are both an accomplishment and a loss. Leaving care restimulates unresolved issues related to the original placement, forcing the individual to relive early separations (Gordy-Levine, 1990). This can stimulate regression and increased acting out by a young person, precisely at a time when expectations for mature behavior may be greatest. Given the scope of these difficulties, there as been increased recognition in North America of the importance of specialized support for youth leaving care. However, there are huge variations in what is provided in different states and provinces because the nature of this transition is poorly understood.

Over the last decade, it has been observed that the normative transition to adulthood is longer than ever. The milestones that have traditionally signaled the attainment of adult status (leaving home, achieving financial independence, getting married, and becoming a parent) seem to be established relatively late in the industrialized world when compared with previous generations (Furstenberg, Rumbaut, 
\& Settersen, 2006). Individuals in their 20s commonly live with their parents, and those who leave often return more than once before permanently launching themselves in their late 20s or their early 30s (Mulder, 2009).

These developments have been observed so consistently that Jeffrey Jensen Arnett, an American developmental psychologist, proposed that a new life stage be added (Arnett, 1998). He coined the term "Emerging Adulthood" for this period, which lasts from the late teens until at least the mid-twenties (approximately 18 to 26). Arnett explained that there are concerns and experiences that are unique to the transition to adulthood and that Emerging Adults are engaged in processes that set them apart from adolescents and young adults. Also characteristic of Emerging Adulthood is residential instability, as these young people experiment with different living situations punctuated by periodic returns home (Arnett, 2007). While some aspects of this stage were previously subsumed in theories of adolescence, adolescent experimentation gives way to more focused exploration in Emerging Adulthood, which in turn results in the establishment of a stable, identity-based lifestyle (Arnett, 2007).

Arnett's research has indicated that most twenty-somethings in the community have mixed feelings about reaching adulthood. The achievement of adult responsibilities is a gradual process, which optimally involves protracted periods of practicing at independence with family standing by to provide a safety net. If all goes well, individuals can achieve an increasing sense of well-being through the emerging adult years, while launching themselves with confidence into adult life. At the same time, long term study suggests that emerging adults whose transition is compromised by a lack of internal and external resources exhibit persistant difficulties which in turn have a negative impact on adult adjustment (Osgood et al., 2005). Youth aging out of care constitute a significant proportion of these failed emerging adults, whose difficulties navigating this critical transition can have a lifelong impact.

Based on these shifts in thinking about transitions to adulthood, this author undertook to learn more about how home leaving in Emerging Adulthood could inform intervention with youth aging out of care (Mann-Feder et al., 2010). The first phase of the research, in which 30 university students were interviewed about home leaving, resulted in the identification of important themes in the normative transition to independent living (Mann-Feder et al., 2010). It should be noted that all of the young people in this study attended a large urban university and none of them lived in residence. The following are findings from the first wave of data analysis, which used consensual qualitative research (Hill, Thompson, \& Williams, 1995) methodology.

It appears that moving out is a disorganizing experience for all young people. One assumption driving the research was that when young people leave home because they wish to do so, the transition is less daunting than when youth are forced to move as they age out of care. Our home leavers described the transition to independent living as a crisis which could not be anticipated or prepared for. It catapaulted them into a period marked by fear and anxiety, despite the fact that they had chosen to move out in seach of privacy and independence. Partipants 
reported that being on their own presented them with unexpected challenges and that worries about money and new responsibilities were compounded by loneliness, roomate problems, and feelings of being overwhelmed. Most stated that they learned the instrumental skills needed (cooking, cleaning, etc.) once they moved and that no amount of preparation would have helped them deal with the intial dramatic impact of leaving. Many reported an initial experience of "going crazy" or losing control (partying too much, staying out late, etc.) when they first moved out. The research team was surprised at the degree to which these reports of the normative transition to independent living resembled the experiences of youth leaving care documented in earlier research (Mann-Feder \& White, 2004).

At the same time, there were important stabilizers in the lives of youth leaving home that made a difference in the degree to which they experienced the intial difficulties in the transition and how well they adapted over time. Internal assets that made a difference were the ability to plan, feelings of excitement about being independent, and the confidence that came from overcoming challenges as they arose. Participants, who had been on their own for short periods prior to moving, even if it was only for a short trip, seemed to weather the initial crisis more easily. Important external assetts came in the form of parental support and encouragement. The awareness that family would step in if things really deteriorated was generally cited as the most significant stabilizer. This lends strong support to Arnett's concept of the parental safety net and its critical role in Emerging Adulthood (Arnett, 2007). Of note is that most participants stated clearly that they did not wish to resort to turning to their parents for back up. They relied instead on peers as mentors when they needed advice and emotional support. This is an important finding because it has been documented that youth leaving care are often isolated from their peers and do not enjoy the same supportive friendship networks as young people in the community (Mann-Feder \& White, 2004).

These preliminary results, considered in light of the theory of Emerging Adulthood, have important implications for intervening with youth in care in the transition to independent living.

1. Our programs must change to reflect the complexity, volatility, and protracted nature of transitions to adulthood, especially for this disadvantaged group. Many agencies currently focus on providing programs of preparation for independent living. It may be that using available resources to provide support during the transition might be more critical.

2. Prior research suggests that most substitute care resources are not currently designed to be flexible enough to allow for a gradual transition, which in turn exacerbates the challenges of transitioning to adulthood (Mann-Feder \& Guérard, 2008). We offer few opportunities for experimentation with autonomy, and even short leaves from care could allow a young person to experience being on their own as part of a transition to independent living. 
3. We do little to assist young people in addressing the difficult emotions associated with the transition from care to adulthood. Youth leaving care can be volatile and acting out. We need to adopt a nonpunitive approach and normalize the expression of feelings.

4. Agency policies and procedures that would allow for brief returns to care after discharge would go a long way in providing the perception of a safety net. Even if respite stays in care are not feasible, building in opportunities for visits or meals in their old units would provide youth leaving care with an experience of continuity and back up.

5. An emphasis on building strong peer connections among cohorts of youth leaving care is essential. Not only can it compensate for the lack of family support, it utilizes a natural resource without necessitating additional funding or major changes in programs.

6. Expectations for youth leaving care must be reevaluated. Front line workers, managers, and the youth themselves need to understand that the transition to independent living is a normative crisis, which, like other developmental turning points, will disrupt the individual's current level of functioning (Goodman, Schlossberg, \& Anderson, 2006). Adaptation to living on one's own takes time and support, but with support, the initial instability can evolve into a period of increased adaptation.

\section{References}

Arnett, J.J. (1998). Emerging adulthood: A theory of development from the late teens through the twenties. American Psychologist, 55, 469-480.

Arnett, J.J. (2007). Aging out of care: Toward realizing the possibilities of emerging adulthood. New Directions in Youth Development, 113, 151-161.

Child Welfare Gateway (2006). Family reunification: What the evidence shows. Available at http://www.childwelfare.gov/pubs/issue_breifs/family_reunification/

Flynn, R. (2003). Resilience in transitions from out-of-home care in Canada: A prospective longitudinal study. Unpublished research proposal.

Goodman, J., Schlossberg, N., \& Anderson, M.L. (2006). Counseling adults in transition: Linking practice with theory ( $3^{\text {rd }}$ Ed.) New York: Springer.

Gordy-Levine, T. (1990). Time to mourn again. In A.N. Maluccio, R. Krieger, \& B.A. Pines (Eds.), Preparing adolescents for life after foster care. Washington, D.C.: Child Welfare League of America. 
Hill, C., Thompson, B., \& Williams, E. (1997). A guide to conducting consensual qualitative research. The Counselling Psychologist, 25(4), 517-572.

Mann-Feder, V. (Ed.). (2007). Issue editor`s notes. Transition or eviction? Youth exiting care for independent living. [Special Issue]. New Directions in Youth Development, 113, 1-8.

Mann-Feder, V., Eades, A., \& Sobel, E. (2010). Leaving home and leaving care: Sources of resilience in emerging adulthood. Pathways to Resilience Conference II. Halifax, Nova Scotia: June.

Mann-Feder,V., \& Garfat, T. (2006). Leaving residential placement: A guide to intervention. Relational Child and Youth Care Practice, 19(40), 66-72.

Mann-Feder, V., \& Guerard (2008). Organizational factors in the transition to independent living. Unpublished manuscript.

Mann-Feder, V., \& White.T. (2004). Facilitating the transition to independent living: Reflections on a program of research. International Journal of Child and Family Welfare, 6(4), 204-210.

Mulder, C. (2009). Leaving the parental home in youth adulthood. In A.Furlong, (Ed.), Handbook of Youth and Young Adulthood: New Perspectives and Agendas. New York: Routeledge.

Osgood, D.W., Foster, E.M., Flanagan, C., \& Ruth, G.R. (2005). Introduction: Why focus on the transition to adulthood for vulnerable populations. In D.W. Osgood, E.M. Foster, C. Flanagan, \& G.R. Ruth (Eds.), On your own without a net: The transition to adulthood for vulnerable populations (1-26). Chicago: University of Chicago Press.

Rutman, D., Barlow, A., Alusik, D., Hubberstay, C., \& Brown, E. (2003). Supporting young people`s transitions from government care. In K. Kufeldt \& B. McKenzie (Eds.), Child welfare: Connecting research, policy and practice (pp.227-238). Waterloo, Ontario: Wilfrid Laurier University Press.

Stein, M. (2006). Research review: Young people leaving care. Child and Family Social Work, 11, 273-279.

Tweddle. A. (2007). Youth leaving care: How do they fare? New Directions in Youth Development, 113, 15-32. 